\title{
A Call for Transformative Learning in Southern Africa
}

\author{
Using Ubuntu Pedagogy to Inspire Sustainability Thinking and Climate \\ Action
}

Yovita N. Gwekwerere and Overson Shumba

\begin{abstract}
People in Southern Africa face escalating levels of risk and uncertainty, and consequent vulnerability, because of multiple stresses, including climate change, environmental degradation, HIV/AIDS, poverty, and political instability. Considerable and sustained efforts in education for sustainable development (ESD) are noteworthy in helping communities to tackle these problems and to endeavor to become more sustainable. In Southern Africa, many factors make realizing action-oriented and transformative learning an immense challenge. First, historical antecedents have resulted in a curriculum that reflects the colonial past and thus impinges on the framing and internalization of curriculum reforms inspired by an ESD frame of reference. Second, the region faces roadblocks similar to those identified by Kwauk in 2020, impeding the development of transformative learning for climate action. In this chapter, we probe these challenges in light of revised curriculum frameworks in Zambia and Zimbabwe. We use teacher and student voices from a baseline study conducted in 2015 to show gaps in curriculum implementation. The chapter suggests that the adoption of a pedagogy inspired by an Afrocentric philosophy, Ubuntu, is a way to transform learning in the direction of sustainability and of thinking and taking action to address climate change.
\end{abstract}

\section{Keywords}

Ubuntu pedagogy - climate action - transformative learning -transformative pedagogy - education for sustainable development - Southern Africa - environmental degradation

(C) UNESCO IBE, 2021 | DOI: 10.1163/9789004471818_011

This is an open access chapter distributed under the terms of the CC BY 4.o License.

Yovita N. Gwekwerere and Overson Shumba - 9789004471818 
In response to UNESCO's Decade of Education for Sustainable Development of 2005-2014, the African Union in Agenda 2063 envisions "the Africa we want", and it calls for an education and skills revolution (African Union, 2014). In this regard, the Continental Education Strategy for Africa (CESA 2016-2025) envisions that education systems need to transform education and to achieve Agenda 2063 (African Union Commission, n.d.). The pursuit of such transformation must take into account the challenges and vulnerabilities faced by African societies in general, and the inadequate quality and the lack of relevance of their education systems. The opening chapter of the book Schooling for Sustainable Development in Africa identifies some of these challenges and vulnerabilities:

As the twenty-first century continues to unfold, African societies are characterised by the continuing effects of a long history of colonial intrusion, the challenges associated with establishing new societies, and governance structures, following the post-195os' independence period, and a complex array of risks and uncertainties associated with the more recent spread of hyper-capitalism, globalisation and earth system degradation. (Lotz-Sisitka \& Lupele, 2017, p. 3)

The history of education in Africa dates back to the colonial era of the 180os. Zambia and Zimbabwe inherited a British system of education. This colonial intrusion introduced a content-focused and examination-driven Eurocentric curriculum that lacked both relevance for African students and quality. Its lack of reference to local examples and environments alienated learners. Nevertheless, much of this style of education has persisted through the many decades since independence. In spite of localized reform efforts over the years, curriculum changes have failed to erase the colonial vestiges. This has made it difficult to tailor the education systems to the African context, so that they may address escalating levels of risk and uncertainty and vulnerabilities stemming from multiple stresses, including climate change, environmental degradation, HIV/ AIDS, poverty, and political instability (Shackleton \& Shackleton, 2012). These vulnerabilities are likely to worsen because of poor-quality education that lacks not only relevance but also any approaches that might inspire and energize climate action. Climate change is the key driver of vulnerabilities in Africa; it exacerbates inequality and makes poverty-reduction goals much more difficult to attain (Islam \& Winkel, 2017). Given the role of climate change, climate change education ought to constitute an important, possibly indispensable, 
aspect of climate action, especially since individual and collective behaviors must change. Anderson (2012) suggests that climate change education must develop relevant skills and content knowledge for climate action, including creating safe, climate-resilient, and sustainable learning spaces.

In Southern Africa, realizing action-oriented and transformative learning for climate action is an immense challenge, owing to a large number of factors and several roadblocks to educational quality, including the ones that Christina Kwauk (2020) fleshed out in her reflective concept paper. These roadblocks include: (a) a historical antecedent that has impinged on the framing and internalization of ESD-inspired curriculum reforms; (b) lack of resources to support teacher agency and leadership in transformative learning for climate action; and (c) lack of curriculum connections to local traditions and real-life challenges and vulnerabilities confronting the learners. This chapter analyzes these three roadblocks and provides a roadmap toward radical transformative pedagogies for sustainability and climate action. Using a combination of analysis of curriculum revisions and anecdotal evidence from a baseline study conducted in Zambia and Zimbabwe, we will highlight some positive curriculum reforms undertaken by both countries in the past decade, as well as discussing implementation roadblocks that remain. We propose solutions toward what Vogel et al. (2015) called a transformative learning journey, guided by the African philosophy of Ubuntu.

\subsection{Defining Transformative Learning and Ubuntu Philosophy}

unEsco, through its leadership of the Decade of Education for Sustainable Development (2005-2014) has demonstrated the importance of ESD in positively transforming individuals and societies to produce overall responsible global citizens. Such transformation occurs when educational programs are meaningfully engaging and when the level of participation in learning processes is high - for example, when knowledge and skills are relevant to local contexts and needs (Bangay \& Blum, 2010). However, ESD learning processes are complex and do not occur through simple transmission of information; they entail a complex process of acquisition, accommodation, interpretation, and capacity-change, leading ultimately to individual or societal transformation (Bangay \& Blum, 2010).

UNESCO (2009) suggested that to transform the individual and society, education must be practice-centered and focused on solutions. Engaging learners in action-centered learning for change helps them experience and reflectively review their participation in climate change solutions. Transformative methodologies ought to be culturally situated and learner centered. They require teachers to have good knowledge and understanding of the content they are 
responsible for and its application to their contexts. UNESCO (2009) further emphasizes the need for well-researched, participatory, and practice-centered methodologies that ensure maximum benefit and promote effective change.

Transformative learning approaches can be realized and justified through the adoption of the Afrocentric philosophy Ubuntu and its associated community practices. Ubuntu is the fundamental ontological and epistemological category in African thought among Bantu-speaking people. Van Wyk (2014) defines Ubuntu as a way of thinking from an African perspective that is based on the principles of inclusivity, cultural specificity, critical awareness, commitment, and political awareness. Ubuntu translates as "I am because we are". It is "humanity toward others". Hence an individual is part of a collective. Grosser and Lombard (2008) suggest that Ubuntu is a "collective cognitive" model (that is, a model consisting of socially constructed, shared definitions), which locates the well-being of the community above the self-interests of the individual. It thus provides a different perspective and paradigm of "knowledge construction" (a less traditional, more active, collaborative way for a learner to gain understanding). The Ubuntu philosophy is considered humanistic and ecologically sustainable (Shumba, 2011; Museka \& Madondo, 2012). Because of all these characteristics of Ubuntu, we contend that it can provide a framework for ESD and climate action, in which learning is a participatory democratic process with opportunities for intergenerational learning for sustainability and climate action.

Pedagogical practices in educational institutions in Southern Africa are frequently at variance with pedagogical practices in social institutions; the family and the community involve group dynamics characterized by participation, interaction, and collective decision-making and action based on lived experiences, be they economic, social, environmental, or cultural. Learning and being educated is purposeful; the individuals become schooled for their place and responsibilities in the family, the community, and society. Ubuntu thus provides a perspective for considering what ought to be taught and a context in which to think about socio-ecological risks posed by climate change, environmental degradation, and degradation of social traditions and a cultural ethos. It can provide a perspective for reframing notions of educational quality and relevance, and for re-examining mainstream pedagogical practices in educational institutions. Shumba (2011) and Museka and Madondo (2012) make a case for a relevant environmental pedagogy informed by Ubuntu philosophy. Museka and Madondo (2012) go on to assert, "This philosophy advocates a holistic approach to education in which human character is developed and fine-tuned for sustainable lifestyles" (p. 264). This view is quite important to the notion we propose of "learning as connection" (Lupele \& Lotz-Sisitka, 2013; 
Shumba, 2017), whereby concept and context converge in meaning-making in local societies around issues such as environment, sustainability practices, and climate change (Lotz-Sisitka, 2013). We see the possibility of an Ubuntu-inspired pedagogy as benefiting education for climate action. In the following sections, we provide an analysis of curriculum reforms in Zambia and Zimbabwe and highlight some roadblocks to achieving ESD goals. Finally, we share some case study examples to demonstrate how schools can embrace Ubun$t u$-inspired pedagogies and dismantle the roadblocks. Highlighted

As mentioned earlier, the education systems that Zambia and Zimbabwe inherited lacked relevance, practiced a pedagogy modeled around teacher-centered transmission of information, and had a curriculum devoid of any local examples or traditions. Some of these pedagogical practices have persisted since independence, despite curriculum reforms seeking to address them. Since gaining independence from Britain in the 196os (Zambia) and 1980s (Zimbabwe), curriculum reform focused first on democratization of education to eliminate inequalities, and later on the need to localize and contextualize, that is to change the curriculum so that it would incorporate local content and local traditions. The most recent curriculum reforms have focused on shifting educational paradigms, including addressing an ESD frame of reference. These reforms also seek to build and strengthen a national ethos and identity.

For both countries, we will focus on primary and secondary curriculum reforms in the second decade of the 21st century. The Zambian National Curriculum Framework (Curriculum Development Centre, 2013) and the Zimbabwean Curriculum Framework for Primary and Secondary Education 2015-2022 (MoPSE, 2016) have proposed transformative curriculum frameworks. Three goals of the frameworks that we will analyze are related to quality education and ESD, and they are: (a) adoption of a heritage-based approach guided by Ubuntu philosophy; (b) integration of "cross-cutting" (discipline-spanning) issues for ESD learning; and (c) expectations as to teacher roles and pedagogical approaches. For each goal, we will provide an analysis and highlight some roadblocks to achieving it.

\subsection{Heritage-Based Approaches Guided by Ubuntu Philosophy}

The focus of a heritage-based approach is redesigning the curriculum to make it relevant to the local context: local cultures, local resources, and examples 
from local environments. One hoped-for result is to stimulate action and innovation. The heritage approach acknowledges inherited African knowledge, landscapes, traditions, and culture, such as, for example, respectful and harmonious utilization of, and existence with, nature. An affirmation of the African cultural identity has been missing from the Eurocentric curriculum, and as a consequence, local cultures and local knowledge are viewed as inferior. In both countries, adoption of a heritage-based philosophy in education, science, and technological developments inspires innovation and creativity. It also helps to localize the curriculum and legitimize the indigenous knowledge, values, and practical skills that learners acquire in their home environments.

The curriculum frameworks of both countries stress values and the adoption of Ubuntu philosophy (MoGE, 2019; MoPSE, 2016). As described earlier, Ubuntu is a model that supports collective agency. This philosophy epitomizes universal human interdependence, solidarity, humaneness, and the sense of community common in Africa (MoGE, 2019). It underpins beliefs and values included in the curriculum such as political sovereignty and self-governance, interdependence, mutual support, respect, discipline, and readiness to help others. Moral uprightness and pride in cultural identity and heritage permeate the curriculum. "Consequently, such a system should offer learners experiences and opportunities that nurture self-actualisation, promote a sense of community and patriotism" (MoPSE, 2016, p. 11).

Despite changes to the curriculum to include Ubuntu values, local content, and local traditions, the curriculum is still theoretical and designed around a "teacher-transmits-information" model of pedagogy that will not achieve the desired outcomes. Such pedagogical practices leave little room for connection to students' lived experiences, valuable indigenous ways of knowing, indigenous explanatory frameworks, indigenous practices, or indigenous technologies.

\subsection{Aligning the Curriculum Frameworks to ESD and Integrating Climate Change}

Both curriculum frameworks emphasize integration of cross-cutting issues and ESD principles into different academic subjects. The curriculum identifies, for example, climate change and HIV/AIDS as cross-cutting issues, for integration into subjects such as science and geography (MoGE, 2019). Mining the experiences of local communities and their fund of knowledge (as prescribed by a heritage-based approach), and combining them with general scientific and technological knowledge, also offer great opportunities for integrating ESD and climate action.

We want to acknowledge the progress of the curriculum frameworks in their attention to issues of quality education and of their being guided by ESD 
principles. However, the frameworks offer no specific guidelines as to how teachers should handle ESD and climate change education in relation to quality education and transformative learning. Although the curriculum revisions incorporate features that represent reasonable steps toward this goal, they do not adequately frame the steps in relation to ESD and transformative learning for climate action.

This shortcoming also relates to the problematic nature of the current definition and framing of ESD, which do not spell out how it should be translated and redesigned to fit the local context of the schools. For example, the Zambian curriculum framework defines ESD as

a distinctive form of environment related education which focuses on adopting an educative approach to sustainability issues in order to improve the capacity of learners to comprehend, participate in and become better at resolving the contentious clash of ecological, social and economic interests in our environments. (Curriculum Development Centre, 2013, p. 22)

The above guidance would not help teachers see how radical a transformation an ESD perspective requires, considering that study of the physical environment has traditionally been an integral part of science and geography classes. The teachers we interviewed during the baseline studies conducted in both countries revealed that they lacked understanding of the definition of ESD and of how to implement it. One Zimbabwean teacher said:

The first thing that we need is to understand what [ESD] is. Because you cannot teach something you don't understand; so you need to understand what it is and then what is involved.

This unfamiliarity with the concept of ESD, and with its implementation, is a major roadblock to implementing ESD pedagogy in favor of climate action. It means that teachers would need not only pedagogical support, but also resources, to help them not only implement an educative approach to sustainability, but also to understand what ESD is.

In addition, although the curriculum frameworks emphasize integrating climate change into the curriculum, they fail to specify ways to cross-link climate change education all across the curriculum, and they make no mention of climate action. According to the Zambian framework, climate change should be taught in two subjects (science and geography). The framework also presents climate change as predominantly an ecological problem: 
It is important that the school curriculum provide for this education so that learners become aware of the ecological aspects of the climate crisis and learn how to contribute towards preventing and combating the issue. (Curriculum Development Centre, 2013, p. 22)

It is unclear how climate change represented this way in the curriculum framework would translate, throughout primary and secondary school levels, into lessons and experiences that would lead to learning outcomes specific to non-science subjects. Vogel et al. (2015) observe that to educate the next generation to understand fully the complex climate system, and climate action, requires "carefully rethinking paradigms and ways in which curricula and knowledge about climate change are currently framed" (p. 8o).

Specific to climate action, we note that in Zambia, the National Policy on Climate Change aims, among other things, to strengthen and mainstream climate change in the school curriculum. The education ministries are not, however, part of the Climate Action Steering Committees, and the responsibility for climate change education is not allocated to any ministry (Policy Monitoring and Research Centre, 2017). This lack of coordination reduces the chances that actions guided by the policy can spread rapidly and effectively through the school system.

In addition, this particular configuration of responsibility reduces the likelihood that capacity-building for climate change education in schools gets funded. Findings from the baseline studies showed that teachers lacked such resources as textbooks and other up-to-date materials for teaching about climate change, and student surveys showed that students get most of their knowledge about climate change from the media, which can lead to misconceptions, as illustrated by the following remark from a Zambian learner:

Because of the same gases, I remember last month on the news, they said that Zambia will be experiencing heat waves for three days, and it was because of the same gases that we had direct rays of sunlight through our skins. The same gases also help in destroying the ozone.

This kind of lack of understanding demonstrates another roadblock to achieving the goals of ESD and climate change education. An understanding of climate science is critical for students if they are to take action to mitigate climate change.

\subsection{Teacher Roles and Pedagogical Approaches}

The curriculum frameworks lay out teachers' roles and professional standards: "ability to make connections, and to integrate crosscutting issues, ability to 
customise curricula and teaching and learning materials, and to participate in communities of practice" (MoGE, 2019). They endorse particular pedagogical practices: learner-centered approaches, performance assessments, action research, case studies, active participation of parents, and the need for "deep learning" (MoGE, 2019). Although both countries are seeking to challenge educational traditions, the curriculum frameworks tend to stress the reproductive function of education, with the teacher playing the central role as the reservoir of knowledge and the agent of its transmission.

Achieving three goals - an outcome-based approach, an alignment to ESD, and climate change action - requires radical transformation, transformation that will enable the adoption of learner-centered inquiry (MoPSE, 2016; MoGE, 2013) and deep-learning pedagogies (Fullan \& Langworthy, 2013) that support "expansive" learning (Lucas et al., 2013). Deep learning is concerned with developing the learning, creating, and "doing" dispositions that young people need in order to thrive now and in their futures (Fullan \& Langworthy, 2013). Expansive education has the explicit focus of developing a "learning disposition" or mentality, knowledge, and a mindset geared to dealing with complexity and difficulty. It aims to engage learners with the outside world and the local community (Lucas, 2019). With these approaches, roles of teachers change radically; they become facilitators and activators, that is to say, agents of change, working with learners to "co-create" (collaboratively arrive at) knowledge, ideas, and actions for innovative change (Fullan \& Langworthy, 2013). Teachers using these approaches are meant to model and practice what they teach.

In our baseline study, both teacher and student participants voiced concerns about lack of leadership in transforming learning to facilitate sustainability and climate action. As a Zambian teacher noted:

No capacity. [Teachers] always think it requires managers to organize and do [environmental clubs]. Even those of us that have relative knowledge about the environment, starting such a thing, talking about setting up clubs, teaching the students ... there are other things I need to do. Time is a factor.

Lack of funding, lack of resources for implementing extra-curricular activities, and lack of training also leave teachers to figure out ESD on their own, in most cases. Without an explicitly defined vision of the implementation of ESD and without support of teachers in its implementation, the curriculum changes alone will not be enough to transform learning in the hoped-for 
direction, and the gap between the intended curriculum and the implemented curriculum will persist.

\section{Dismantling Roadblocks through Ubuntu-Inspired Pedagogy}

The above discussion of the curriculum frameworks shows that these two countries lack a radical vision for ESD and climate change education. What needs to be done? In this section, we reflect on that question. Defining new goals for learning relevant to this new era is one thing; defining the processes of achieving those goals is an altogether other challenge (Fullan \& Langworthy, 2013). The complexity and rapidity of change in today's world, and the roadblocks (Kwauk, 2020), complicate matters. We contend also that further complications will ensue if education in Africa continues to be guided by a Eurocentric philosophical framework. A disconnection exists between the information and knowledge circulating in the education system and their relevance to the life and well-being of individuals and their communities (Lotz-Sisitka, 2008; Shumba et al., 2008; Shumba, 2017). We contend that radical transformative pedagogical approaches guided by Ubuntu will facilitate individual change and societal transformation that will lead to sustainable futures. Such pedagogies require that students learn beyond the walls of the classrooms and outside the "siloed" (compartmentalized and walled-off) subject areas. The new pedagogies connect students to their communities, giving them the opportunity to learn from the community and to take action for the community.

The notion of "learning as connection" features in the discourse on educational quality. It features in a view of learning as a transformative journey that involves an active interfacing of context and concept, an interfacing that results in the learners' making connections between the socio-cultural, the socio-ecological, and personal and communal lifeworlds and experiences (Lupele \& Lotz-Sisitka, 2012; Shumba, 2017). On this journey learners need to engage with a range of "knowledges" (bodies of knowledge) existing in their communities, including those informed by an African Ubuntu perspective (Vogel et al., 2015). Ubuntu-inspired pedagogies will enable learners to connect their background knowledge, experiences, and cultures to what they learn in school (Shumba, 2017). Teachers and students have an intimate understanding of their local environments, traditions, and lived experiences that are not part of the curriculum, and omitting mention of them makes education irrelevant, leaving teachers and students constantly trying to reconcile the curriculum content and their day-to-day realities. For example, when we asked participants in the 
baseline study about the environmental challenges they are experiencing in their communities, forest fires were a major concern for most, and one Zimbabwean teacher clearly articulated her views on why people start forest fires:

I think [the fires] are something to do with culture. We have learned to think that [after a growing season] we should burn [the field stubble].

The practice she was referring to stems from the traditional slash-and-burn agricultural practices known in Zambia as chitemene. The teacher went on to discuss how the geography and science curriculums, into which ecosystems and climate change are integrated, do not make such a connection. In such a case, Ubuntu-inspired pedagogies could help teachers connect such local traditions to current environmental issues and help learners understand how harmful some traditional practices are to the environment, hence empowering them to take leadership for climate action and sustainability.

\subsection{Examples of Ubuntu-Inspired Pedagogies Aligned to ESD Learning Processes}

In this section, we provide some examples of ESD and climate change education projects that non-governmental organizations (NGOS) have offered to schools in both countries. We have identified processes involved in these projects as forms of Ubuntu-inspired pedagogies that can help with dismantling the roadblocks to quality education in a time of climate crisis. These processes enrich learner experiences through community engagement; through collaboration with the community, with NGOS, and with governmental partners; and through enlistment of all these groups as co-creators of learning projects. Such pedagogies enable young people to learn from, and for, their communities and empower young people to take leadership in climate action. In Table 10.1, we provide three case studies demonstrating real experiences of ESD for climate action and sustainability that connected young people to their communities and empowered them to take action. For each case we briefly describe the project (Column 1) and identify the Ubuntu pedagogical lens (Column 2). We see potential ways for the identified practices to be enhanced in accordance with deliberate heritage approaches and an ESD perspective (as suggested in Column 3). The Ubuntu tenets that are common across the three examples include care and responsibility for the local environment, conservation practices in local environment, cooperation and partnership, social learning, peer education, and collaboration and partnerships. From these Ubuntu tenets emanate ESD learning processes, such as ethic of care, social and "situated" (place-based) learning, group-learning methods, youth leadership and agency, 
TABLE 10.1 Models for learning as connection and collaboration, and the inferred Ubuntu and ESD connections

Case study

Inferred Ubuntu-informed ESD

\section{Example of Ubuntu tenet in the case}

\section{Possible \\ Ubuntu-informed ESD}

Case study 1. Community service projects at Care and responsibility for Social and situated Kucetekela Foundation in Lusaka, Zambia. the environment learning (http://kucetekelafoundation.org/ program/\#community)

This NGO works with local high schools to promote environmental protection programs that empower youth to become leaders and transform their communities to take action to mitigate climate change. Students conduct research, then disseminate the information to other youth at schools and communities by way of storytelling and making art from recycled materials. The NGO works in partnership with various agencies, including Lusaka Municipality, the Zambia Environmental Agency, Pestalozzi education center, and various community partners.

Case study 2: Eco-schools environmental clubs.

Mukuvisi Woodlands

(http://www.mukuvisiwoodland.co.zw/ Mukuvisi\%2oEco\%2oSchools\%2O Prog.html), an NGO in Zimbabwe runs an Eco-Schools Programme themed "My Environment, My Future, My Responsibility". It empowers learners through school environmental clubs and demonstrates to teachers how to integrate environmental education into local school policies and into the curriculum. Students engage in hands-on change projects on themes they choose, leading to action to mitigate climate change, e.g., tree planting.

\section{School and}

Conservation practices in community interface local environment

Situated learning

Local heritage

Youth leadership and agency

Heritage approaches

\author{
Conservation practices in Group learning \\ local environment methods \\ Community service, Learning about \\ cooperation and global issues through \\ partnership learning about local \\ issues \\ Storytelling \\ Peer education

\section{Community} \\ engagement \\ School and community- Networking \\ based organization \\ between school and \\ interface and partnership community-based \\ organizations \\ Care and responsibility for Ethic of care \\ environment
}


TABLE 10.1 Models for learning as connection and collaboration, and the inferred Ubuntu and ESD connections (cont.)

Case study

Inferred Ubuntu-informed ESD

\section{Example of Ubuntu}

tenet in the case

Care and responsibility for School and

Case study 3: Smart Climate

Action Learning Resources and

Partnerships Zambia (scAZ)

(https://conservationzambia.org/u4cc/)

\& Unite for Climate Change (U4CC)

(https://conservationzambia.org/smart-

climate-actions-zambia-scaz/)

The Wildlife and Environmental

Conservation Society of Zambia

(https://conservationzambia.org) runs the Social learning

SCAZ and U4CC projects. SCAZ is a Smart

Climate Action Toolkit, and the U4CC

is a youth climate change ambassadors

project. Both projects complement in

demonstrating climate-smart actions and

building leadership capacity for climate

action. The SCAZ promotes learning by

carrying out experiments, conducting

case studies, modeling scenarios,

and taking a stand on local issues.

U4CC promotes peer education and

actions, including tree planting, waste

management projects, student-led radio

shows, and community education. community interface

Conservation practices in

local environment

Community service,

cooperation, and

partnership

Peer education
Inter- and intra-

generational learning

Situated learning

Values

clarification and

taking a stand

Promoting collective agency
Possible

Ubuntu-informed ESD

use of local environments for learning about global issues, community engagement, and networking between school and community-based organizations.

Case study 1 features the Kucetekela Foundation, an NGO that, in sharing project information with us, inspired our use of Ubuntu pedagogy in this chapter. The foundation provides opportunities for high school students to become climate change champions through research, through engagement in community service projects, and as waste management and climate change ambassadors. In addition to the Ubuntu tenets listed above, this project also exemplifies community service and storytelling. Case study 2 features Mukuvisi Woodlands, an NGo that promotes and supports educators and learners to 
implement change projects through environmental clubs. In addition to the Ubuntu tenets listed above, this project also exemplifies the valuing of one's heritage through improving one's self-image and appreciating one's environment. Finally, case study 3 features the Smart climate action and climate change ambassadors programme that empowers young people and builds leadership capacity for climate action. In addition to the Ubuntu tenets listed above, this project also exemplifies community service and taking a stand on behalf of the environment.

Although these examples are not representative of pedagogical approaches used in the mainstream education system, we see them as models of ESD and climate change education approaches that have been adopted by certain schools in Southern Africa that have already embraced the Ubuntu philosophy and heritage approaches as suggested in the national curriculum revisions. These model programs empower young people to become sustainability leaders and ambassadors for climate action in their communities and provide the opportunity to dismantle the roadblocks to quality education in a time of climate crisis (Kwauk, 2020).

Each of the case studies in Table 10.1 demonstrates collective agency that encompasses the Ubuntu philosophy of "humanity toward others", as learning becomes part of a collective in which learners, communities, and organizations come together. Given the urgent nature of the climate crisis, there is need to break away from an educational framework guided by the capitalist and individualistic ideals that have led to the current climate crisis. We contend that Ubuntu-inspired frameworks that emphasize a collective cognitive model and place the well-being of the community above individual self-interest is the best way to achieve the ESD and climate change education goals outlined in the curriculum frameworks. Such collective agency will also support adoption of a heritage-based education approach with an underlying Ubuntu philosophy. It also bridges the gap between students' lived experiences and curriculum content, as well as engaging them as co-creators in the generation of the knowledge relevant to solving problems and taking action for climate change.

We take counsel from Lupele and Lotz-Sisitka (2012), who observe that schools and higher education institutions are demonstrably important sites for ESD learning processes, but that they are at the same time inadequate sites for ESD (Lupele \& Lotz-Sisitka, 2012). As indicated in Table 10.1, transformative pedagogy requires crossing of "boundaries" - between schools and communities, between universities and society, and between the world of work and the world of social contexts in which people live and learn.

The indictment of the global education community as lacking a radical vision for education (Kwauk's roadblock number 2, Kwauk, 2020) is accurate in 
the case of these two countries when taken in the context of SDG 13's directive: "Take urgent action to combat climate change and its impacts". This situation may be a result of inadequate participation by policymakers and educators in the formulation of climate action strategies. We noted above the omission of ministries of education in the national steering committee for the National Policy on Climate Change launched in Zambia (PM RC, 2017). However, adoption of Ubuntu-inspired pedagogy can support relevant eco-literacy (roadblock number 1); re-visioning education toward radical learning for climate action (roadblock number 2); and providing the lens through which to question values that promote individualism, domination, control, and exploitation.

\section{$4 \quad$ Conclusion}

The revisions of their curricula that Zambia and Zimbabwe are undertaking foreground particular cross-cutting issues in ESD and climate change: local environments; cultural heritage and Ubuntu philosophy; and the development of competencies. However, more efforts toward radical transformation of the process of education are needed in order to address SDG 4, Quality Education, and SDG 13, Climate Action. We recommend that the education systems in Zambia and Zimbabwe consider the following in order to implement an Ubuntu-inspired pedagogy that would lead to transformative learning in ESD and climate change education:

- The complexity of the ESD learning processes for climate action calls for systematic support for teachers to become change agents for sustainability that is, for them to tackle roadblock number 5 (Kwauk, 2020). They need the kind of training and resources that will help change their narratives and actions, that will move them toward a transformative role as facilitators, activators, and "co-creators" in the generation of knowledge, and as agents of change. After all, ESD and climate change education are about developing competencies that prepare learners to decide and act for a sustainable future.

- Education plays a critical role in the adaptation to, and mitigation of, climate change. The ministries of education should be involved in the climate response task forces in both countries so that they may secure funding for transformative education and come up with practical ways to implement it.

- The case studies in this chapter describe pedagogical practices that are possible to mainstream into education systems as a way of integrating the Ubuntu philosophy into the curriculum. Ministries of education in Zambia and Zimbabwe should consider a whole-of-systems approach to integrating 
existing NGO-funded or NGO-initiated sustainability and climate change programs into the school curriculum.

- In order to transform learning and inspire sustainability thinking and climate action among learners, schools must promote pedagogical approaches that support learning as connection, and collaborate with government agencies, municipalities, NGOs, and other community partners.

\section{References}

African Union. (2014). Africa agenda 2063: The Africa we want. https://au.int/en/ agenda2063/overview

African Union Commission. (n.d.). Continental education strategy for Africa 2016-2025. https://au.int/sites/default/files/documents/29958-doc-cesa_-_english-v9.pdf

Anderson, A. (2012). Climate change education for mitigation and adaptation. Journal of Education for Sustainable Development, 6(2), 191-206.

Bangay, C., \& Blum, N. (2010). Education responses to climate change and quality: Two parts of the same agenda? International Journal of Educational Development, $30(4)$, 359-368.

Curriculum Development Centre. (2013). Zambia national curriculum framework. Ministry of General Education, Zambia. http://www.ibe.unesco.org/fileadmin/user_ upload/archive/curricula/zambia/za_alfw_2013_eng.pdf

Fullan, M., \& Langworthy, M. (2013). Towards a new end: New pedagogies for deep learning. https://michaelfullan.ca/wp-content/uploads/2013/o8/New-Pedagogiesfor-Deep-Learning-An-Invitation-to-Partner-2013-6-201.pdf

Grosser, M. M., \& Lombard, B. J. J. (2008). The relationship between culture and the development of critical thinking abilities of prospective teachers. Teaching and Teacher Education, 24(5), 1364-1375. https://doi.org/10.1016/j.tate.2007.10.001

Islam, S. N., \& Winkel, J. (2017). Climate change and social inequality. Department of Economic \& Social Affairs, United Nations. https://www.un.org/esa/desa/papers/ 2017/wp152_2017.pdf

Kwauk, C. (2020). Roadmaps to quality education in a time of climate change. Brookings. https://www.brookings.edu/research/roadblocks-to-quality-education-in-a-timeof-climate-change/

Lotz-Sisitka, H. (2008). Environmental education and educational quality and relevance: Opening the debate. Southern African Journal of Environmental Education, $25,5^{-12 .}$

Lotz-Sisitka, H. (2013). Think piece: Conceptions of quality and 'learning as connection' - Teaching for relevance. Southern African Journal of Environmental Education, 29, 25-37. 
Lotz-Sisitka, H., \& Lupele, J. K. (2017). ESD, learning and quality education in Africa: Learning today for tomorrow. In H. Lotz-Sisitka, O. Shumba, J. Lupele, \& D. Wilmot (Eds.), Schooling for sustainable development in Africa. Springer.

Lotz-Sisitka, H., Shumba, O., Lupele, J., \& Wilmot, D. (2017). Schooling for sustainable development in Africa. Springer.

Lucas, B. (2019). Why we need to stop talking about twenty-first century skills. https://www.researchgate.net/publication/332864663_Why_we_need_to_stop_ talking_about_twenty-first_century_skills/citations

Lucas, B., Claxton, L., \& Spencer, E. (2013). Expansive education teaching learners for the real world. http://www.expansiveeducation.net/resources/Pictures/

Extract\%2ofrom\%2oExpansive\%2oEducation\%2oon\%2oexpansive $\% 20$ pedagogy.pdf

Lupele, J. K., \& Lotz-Sisitka, H. (2012). Learning today for tomorrow: Sustainable development learning processes in sub-Saharan Africa. SADC Regional Environmental Education Programme.

MoGE [Ministry of General Education]. (2019). Teacher curriculum implementation guide. Ministry of General Education, Zambia.

MoPSE [Ministry of Primary and Secondary Education]. (2016). Curriculum framework for primary and secondary education 2015-2022. http://mopse.co.zw/sites/default/ files/public/downloads/Zim_Curriculum_Framework.pdf

Museka, G., \& Madondo, M. M. (2012). The quest for a relevant environmental pedagogy in the African context: Insights from unhu/ubuntu philosophy. Journal of Ecology and the Natural Environment, 4(10), 258-265.

PMRC [Policy Monitoring and Research Centre]. (2017). National climate change policy. https://www.pmrczambia.com/wp-content/uploads/2017/11/National-Policy-onClimate-Change.pdf

Shackleton, S. E., \& Shackleton, C. M. (2012). Linking poverty, HIV/AIDS and climate change to human and ecosystem vulnerability in southern Africa: Consequences for livelihoods and sustainable ecosystem management. International Journal of Sustainable Development and World Ecology, 19(3), 275.

Shumba, O. (2011). Commons thinking, ecological intelligence and the ethical and moral framework of Ubuntu: An imperative for sustainable development. Journal of Media and Communication Studies, 3(3), 8o-83.

Shumba, O. (2017). Tackling educational quality and epistemological access concerns in science and technology education in Africa: The "learning-as-connection" imperative. African Perspectives of Research in Teaching and Learning, 1(1), 4-21.

Shumba, O., Kasembe, R., Mukundu, C., \& Muzenda, C. (2008). Environmental sustainability and quality education: Perspectives from a community living in a context of poverty. Southern African Journal of Environmental Education, 25, 81-97. 
UNESCO. (2009). ESD contexts, concepts and processes: Global monitoring report on implementation of the UNDESD.

Van Wyk, M. M. (2014). Conceptualizing an Afrocentric-indigenous pedagogy for inclusive classroom environments. Mediterranean Journal of Social Science, 5(4), 293-299. Vogel, C., Schwaibold, U., \& Misser, S. (2015). Teaching and learning for climate change: The role of teacher materials and curriculum design in South Africa. Southern African Journal of Environmental Education, 37(2015), 76-97. 